\title{
Risks and protective factors for triple negative breast cancer with a focus on micronutrients and infections
}

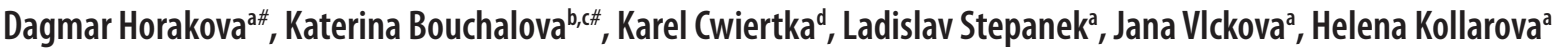

Triple negative breast cancer (TNBC) is an aggressive form of breast cancer (BC) with a poor prognosis. Second, patients cannot benefit from targeted therapy, except for those with BRCA1/2 mutations, for whom poly (ADP-ribose) polymerase (PARP) inhibition therapy using olaparib has recently been approved. As global priorities continue to be epidemiological analysis of $B C$ risk factors and early diagnosis, this review focuses on the risks and protective factors associated with TNBC. A PubMed keyword search for new knowledge on the risks and protective factors for TNBC was carried out. We also found statistical information from current online databases concerning the estimated incidence, prevalence and mortality worldwide of this cancer. Traditional risk factors for BC and TNBC are those related to reproduction such as the age of menarche, age of first birth, parity, breastfeeding and age at menopause. Attention needs to be paid to familial BC, weight control, alcohol consumption and regular physical activity. Epidemiological studies on TNBC provide evidence for protective factors such as regular consumption of soya, seafood, green tea, folic acid and vitamin D. Potential risk factors may include night work and viral infectious agents like human papillomavirus (HPV) and Epstein-Barr virus (EBV). Droplet digital methylation-specific PCR (ddMSP) is a possible new screening method for detection of $B C$ including TNBC. Further research is necessary to validate these new factors.

Key words: triple negative breast cancer, risk and protective factors, micronutrients, human papillomavirus, EpsteinBarr virus, body weight

Received: August 1, 2017; Accepted with revision: March 27, 2018; Available online: May 15, 2018

https://doi.org/10.5507/bp.2018.014

${ }^{a}$ Department of Preventive Medicine, Faculty of Medicine and Dentistry, Palacky University Olomouc, Czech Republic

bInstitute of Molecular and Translational Medicine, Faculty of Medicine and Dentistry, Palacky University Olomouc, Czech Republic 'Department of Pediatrics, Faculty of Medicine and Dentistry, Palacky University Olomouc and University Hospital Olomouc, Czech Republic ${ }^{d}$ Department of Oncology, Faculty of Medicine and Dentistry, Palacky University Olomouc and University Hospital Olomouc, Czech Republic "These authors contributed equally to the work

Corresponding author: Katerina Bouchalova, e-mail: katerina.bouchalova@upol.cz

\section{INTRODUCTION}

Breast cancer (BC) is currently one of significant global public health problems in the non-infectious disease category, mainly in developed countries. Apart from skin cancer, $\mathrm{BC}$ is the most common malignancy in women. Each year, about 1.67 million female patients are diagnosed with $\mathrm{BC}$ worldwide. Approximately half a million women $(522,000)$ die of the condition annually ${ }^{1}$. In the Czech Republic, BC is also the most frequent cancer in women, with an incidence of more than 7,000 new cases per year. The increasing incidence rates observed in the Czech Republic are likely to be linked to an established and successful screening program and aging of the population. In early stages, the treatment is very successful. In clinical stage I-II BC, the relative 5-year survival is over $90 \%$. Yet BC remains the leading cause of death from cancer among Czech women ${ }^{2}$.

Both incidence and survival rates vary. Developed countries (defined by a very high Human Development Index, HDI) have a higher proportion of $\mathrm{BC}$ incidence worldwide (44.7\% of all cases) compared to less developed countries (high, medium or low HDI), with the latter accounting for only $8.8 \%$ of all cases around the world ${ }^{3}$. While in the Northern United States the survival rate is more than $80 \%$, it is less than $40 \%$ in low-income countries, probably due to a lack of diagnostic and screening possibilities ${ }^{3,4}$. Numerous epidemiological analyses have shown a negative association between mortality and a region's development index. In developed countries, diagnostic and treatment methods are more frequently used. Moreover, primary prevention makes girls and women more aware of this condition. The global priorities continue to be epidemiological analysis of risk factors and early diagnosis of $\mathrm{BC}$ disease.

Triple-negative breast cancer (TNBC) is an aggressive form of $\mathrm{BC}$ with poor prognosis. TNBC accounts for 10$20 \%$ of all BC cases and these patients cannot benefit from targeted endocrine or anti-HER2 (human epidermal growth factor receptor-2) therapy, as these tumours lack oestrogen (ER), progesterone (PR) and HER-2 receptors ${ }^{5,6}$. TNBC patients with BRCAl/2 mutations may be treated with poly (ADP-ribose) polymerase (PARP) inhibition therapy using olaparib that has recently been approved by the U.S. Food and Drug Administration (FDA) (ref. $\left.{ }^{7}\right)$. Some patients with metastatic BC may benefit from addition of bevacizumab to chemotherapy ${ }^{8}$; the drug is currently approved by the European Medicines Agency but not by the FDA. TNBC more frequently affects younger patients and is more prevalent in African-American 
women ${ }^{5}$. Moreover, TNBC is a clinically and molecularly heterogeneous disease. It has the highest frequency of somatic rearrangements among $\mathrm{BCs}$ and encompasses at least seven subtypes with different prevalence rates, gene expression profiles, and clinical outcomes. Although it is generally a rapidly progressing and highly malignant disease, its frequent sensitivity to chemotherapy makes it potentially curable if detected at a sufficiently early stage. On the other hand, experiences with neoadjuvant and adjuvant treatment indicate that approximately one third of TNBC cases are chemoresistant, even when using regimens based on the most effective cytotoxic drugs, such as anthracyclines, platinum derivatives, and taxanes ${ }^{9}$. Therefore, there is a focus on a search for risk factors, even selectively for this BC subtype.

\section{TRADITIONAL RISK FACTORS FOR BC AND TNBC}

\section{Reproduction-related factors}

Traditional BC risk factors (Table 1) are those related to reproduction such as the age of menarche, age of first birth, parity, breastfeeding and the age of menopause. These aspects are continuously discussed and the strength of the association between reproductive factors and the development of $\mathrm{BC}$ remains the subject of epidemiological studies. The results have shown that menarche at 14 years or later reduces the risk of and protects against BC (relative risk, RR 0.86; 95\% CI 0.79-1.00). Women giving birth to their first child at the age of 30 or later have a slightly increased risk of the development of BC (RR 1.1). Having a history of three or more births may be a protective factor (RR 0.78) $\left(\right.$ ref. $\left.^{10}\right)$. Another important risk factor is a long interval between menarche and the first pregnancy, especially if longer than 20 years ${ }^{11}$. Breastfeeding remains a significant protective factor against the development of $\mathrm{BC}$ but only if the duration is 12 or more months ${ }^{12}$. Given the current trends such as delaying the first pregnancy until an older age, a shorter duration of breastfeeding due to work obligations and having a mean of 1.2 children among women in European Union countries, accumulation of these risk factors is likely to enhance the effect on the development of cancer. Longitudinal studies investigate whether the risk for $\mathrm{BC}$ is also associated with the concentration of reproductive hormones. Higher premenopausal circulating testosterone levels are linked to the risk of BC. Neither oestradiol nor progesterone levels have shown significant associations. Only after adjustment for age, higher oestradiol levels may be associated with an increased risk of BC in women just before the age of 50 years ${ }^{13}$. In postmenopausal women, higher oestradiol and testosterone levels increase the risk of $\mathrm{BC}(\mathrm{OR} 2.34)$ irrespective of oestrogen receptor positivity ${ }^{14}$.

A meta-analysis of 27 epidemiological studies selectively focused on TNBC proved that breastfeeding has a protective effect even against this type of BC (OR 0.78). The mechanisms of the protective effect remain unclear and require further investigation. The protective effect may be mediated by non-hormonal mechanisms, the immune responses of adhesion and apoptosis of the terminal ductal cells that underlie the resistance to carcinogenesis. The meta-analysis did not specify the duration of breastfeeding necessary for the protective effect; the doseresponse relation was not given but a vast majority of women stated breastfeeding for 6 to 12 months after the birth. Therefore, breastfeeding remains a simple and practical way to prevent TNBC which is far more common in younger women ${ }^{15,16}$. Early age of menarche is not associated with an increased risk of TNBC, while the increased risk of TNBC is associated with delayed first pregnancy ${ }^{17}$.

\section{Genetic factors}

A significantly increased lifetime risk of breast and ovarian cancer (an estimated 7- to 25-fold increase) results from the presence of $B R C A 1 / 2$ gene mutations. These are responsible for more than $90 \%$ of hereditary $\mathrm{BC}$ cases $^{18}$. Approximately $75 \%$ of $B R C A$-mutated BCs are TNBCs. On the other hand, $20 \%(10-42 \%)$ of TNBCs are $B R C A$ mutated BCs (ref. ${ }^{19-21}$ ). Genetic susceptibility to breast or ovarian cancer might also be associated with mutations in other genes such as p53, PTEN, CDH1, PALB2, CHEK2, ATM, RAD51C, STK11, RAD51D, BRIP1, MLH1, MSH2, MSH6 and PMS2 (ref. ${ }^{18}$ ). In daughters of mothers with $B R C A$ gene mutation, the diagnosis is clearly made before the age of 50 years (median 43.85). Screening for BC/ TNBC needs to be focused on genetic counselling and testing of carriers of specific BRCA gene mutations ${ }^{22}$.

\section{Alcohol consumption}

In many epidemiological studies, cancer has been associated with alcohol consumption, although the definition varies among studies. Biological mechanisms and a causal relationship between alcohol consumption and the development of cancer have been reported for $\mathrm{BC}$ as well as for laryngeal, pharyngeal, oesophageal, liver and colorectal cancer. A review of published meta-analyses showed that alcohol increased the risk of BC by $7-10 \%$ per each unit of alcohol consumed daily ( 1 unit of alcohol is equal to $0.5 \mathrm{~L}$ of beer or $25 \mathrm{~mL}$ of $40 \%$ alcohol or $125 \mathrm{~mL}$ of $12 \%$ wine) (ref. ${ }^{23}$ ). Women with high daily alcohol intake (27 units/week) had 51\% higher risk than

Table 1. Risk and protective factors.

\begin{tabular}{lcll}
\hline Traditional risk factors & Ref. & New emerging factors & Ref. \\
\hline Reproduction-related factors & $10-17$ & Night work influence & $46-48$ \\
Genetic factors & $18-22$ & Viruses (HPV, EBV) & $49-54$ \\
Alcohol consumption & $23-28$ & Fish and seafood intake & 45 \\
Low physical activity & 29 & Soyafoods, green tea & 42,44 \\
Body overweight & $30-35$ & Folic acid, vitamin B2, B6, D, zinc, $\beta$-carotene & $36-41$ \\
\hline
\end{tabular}


their abstaining counterparts. In a case-control study, mild to moderate alcohol intake ( 5 units/week) was associated with a slightly increased risk of BC (OR 1.75); the risk was even higher (OR 2.05) with increased alcohol consumption ( $\geq 10$ units/week), as compared with that in abstainers. The strongest association was observed in postmenopausal women ${ }^{24}$.

Some authors point to the fact that the association between alcohol consumption and the development of $\mathrm{BC}$ is modified by the presence of overweight and obesity (defined by the WHO as body mass index, BMI $\geq 30$ ) in women. Epidemiological studies adjusting the association for overweight and obesity show that the correlation between alcohol consumption and BC is not statistically significant (RR 1.01) and the risk is only slightly increased in women with $\mathrm{BMI} \leq 25$ (RR 1.03) $\left(\right.$ ref. $\left.{ }^{25}\right)$. After adjustment for the effects of age, BMI and smoking, a multivariate analysis of higher $\gamma$-glutamyltransferase levels found a slightly increased risk of BC compared to that in women having low levels (RR 1.21) ( ref. $^{26}$ ). Thus, epidemiological studies suggest that alcohol remains a risk factor for $\mathrm{BC}$ but only if consumed in larger amounts. To minimize the risk of $\mathrm{BC}$, mild alcohol consumption is recommended, namely one unit of alcohol daily and probably no alcohol on two days a week. In women who fail to reduce their alcohol consumption, the negative effects should be compensated for by adequate intake of folic acid ${ }^{27}$.

In a large TNBC cohort of postmenopausal women $(n=300)$, Kabat et al. showed that alcohol consumption was not associated with increased risk of TNBC (ref. ${ }^{28}$ ).

\section{Physical activity and body weight risk factors}

Another significant modifiable protective factor potentially reducing the risk of $\mathrm{BC}$ is physical activity. Especially if there is a long interval between menarche and the first pregnancy, as stated above, regular physical activity is associated with a considerably lower risk of BC (RR 0.73) (ref. ${ }^{11}$ ). Similar results were found by Ma et al. ${ }^{29}$ : regular recreational physical activity performed for at least three and a half hours weekly in adulthood is a protective factor against invasive BC (RR 0.71) ( ref. $\left.^{29}\right)$. The study included 4827 women, of whom 348 had TNBC. Both long-term and baseline strenuous physical activity were inversely associated with $\mathrm{BC}$ risk $(P<0.03)$; this association was also confirmed in the TNBC subgroup $(P<0.02)\left(\right.$ ref. $\left.^{29}\right)$.

Epidemiological studies suggest that weight control or a mild weight loss by $5-10 \%$ significantly reduced the risk of BC. In a large population of women $(14,684)$ undergoing mammographic screening for 73 months, an increased risk of BC was determined in obese women (RR 1.32) $\left(\right.$ ref. $\left.{ }^{30}\right)$. Postmenopausal women with primary oestrogen receptor-negative $\mathrm{BC}$ have a more than 5-fold increased risk (RR 5.64) of developing contralateral BC (ref. ${ }^{31}$ ). Similarly, an increased risk of contralateral BC is associated with a weight gain of $10 \mathrm{~kg}$ or more after the initial diagnosis is made ${ }^{32}$.

Few studies have examined the relationship between BMI and the risk of TNBC and the results are inconsistent. No clear relationship between high BMI and an increased risk of TNBC was found. A low positive association was found in case of postmenopausal women who had never undergone hormonal therapy in a study by Phipps et al. ${ }^{33}$. The hypothesis explaining the link between obesity and TNBC is based on the effects of hyperinsulinemia and insulin-like growth factors, which are overexpressed in obese individuals. Similar findings in postmenopausal women, but not restricted to non-users of hormonal therapy were revealed in another study by Phipps et al. ${ }^{34}$. In this large study (TNBC n=307 and oestrogen receptor-positive, $\mathrm{ER}+\mathrm{BC} \mathrm{n}=2610)$, weight change between ages 35 and 50 years was significantly associated with TNBC risk (hazard ratio, HR 1.69, 95\% CI 1.062.71 for a weight gain $>6.0 \mathrm{~kg}$ versus $<2.5 \mathrm{~kg}, P=0.03$ ). Further, women in the highest versus lowest BMI quartile had 1.35-fold (95\% CI 0.92-1.99) and 1.39-fold (95\% CI 1.22-1.58) increased risks of TNBC and ER+ BC, respectively. Compared to women who reported no recreational physical activity, women in the highest activity tertile had similarly lower risks of both TNBC and ER+ BC (HR 0.77, 95\% CI 0.51-1.13 and HR 0.85, 95\% CI 0.74-0.98, respectively), although statistically nonsignificant in the case of TNBC. There was no significant protective effects of regular physical activity and low BMI in the case of TNBC in this study but the authors concluded that TNBC and $\mathrm{ER}+\mathrm{BC}$ were similarly associated with higher BMI and no recreational physical activity in postmenopausal women. However, the underlying biological mechanisms are unclear and these modest associations require further research ${ }^{34}$. Larger TNBC series may also be necessary to validate these results. Given the potentially modifiable nature of both BMI and physical activity, these results ${ }^{34}$ together with data from the above study by Ma et al. ${ }^{29}$ suggest that postmenopausal women might modify their risk of TNBC.

In female survivors of TNBC, an intervention in the form of regular physical activity had a significant impact on their physical condition, quality of life, decreased incidence of obesity and decreases in serum markers of chronic inflammation (C-reactive protein) and interleukin-6; however, exercise failed to affect serum adipokines. Regular aerobic exercise of mild intensity is commonly recommended to female survivors of aggressive $\mathrm{BC}$ to improve the quality of life, lose adipose tissue as a source of hormonal mediators and reduce chronic inflammation ${ }^{35}$. Exercise also reduces the risk of osteoporosis caused by hormonal therapy and chemotherapy.

\section{NEW EMERGING FACTORS FOR BC AND TNBC}

\section{Micronutrients and other food components}

Many epidemiological studies have investigated the relationship between folate intake, circulating folic acid levels and BC. However, the results are inconclusive. Some authors suggest preventive effects of folic acid, in particular with higher alcohol intake ${ }^{36}$, as stated above. Increased dietary intake of folic acid was associated with a lower risk of oestrogen receptor-negative BC, but only in premenopausal women (RR 0.92) $\left(\right.$ ref. $^{37}$ ). Further, high 
plasma levels of vitamin B6 and riboflavin may reduce the risk of $\mathrm{BC}$, particularly in premenopausal women ${ }^{38}$. A large prospective cohort study of women with invasive $\mathrm{BC}$ showed that vitamin $\mathrm{D}$ was beneficial in preventing $\mathrm{BC}$ recurrence ${ }^{39}$. In this study serum vitamin $\mathrm{D}$ concentrations were lower in women with advanced-stage tumours and lowest in premenopausal women with TNBC $\left(\right.$ ref. $\left.{ }^{39}\right)$. However, randomized clinical trials of adequate size and duration with sufficient doses of vitamin D are still lacking ${ }^{40}$.

Combined genetic analyses of 18 DNA-repair nonsynonymous single nucleotide polymorphisms (nsSNPs) and micronutrient intake in TNBC suggest that dietary modulation may prevent or reverse the TNBC phenotype so patients could be treated with less toxic therapies. TNBC was associated with six DNA-repair nsSNPs and/ or three micronutrient deficiencies (zinc, folic acid and $\beta$-carotene). Combined analyses of these nine risk factors showed significant associations with TNBC: OR 2.77 (95\% CI 1.01-7.64) and 10.89 (95\% CI 3.50-33.89) for 2 and at least 3 risk factors, respectively ${ }^{41}$.

Long-term consumption of soya may result in increased expression of tumour suppressor genes and decreased expression of oncogenes, particularly in TNBC. Thus, soya consumption may have a protective effect against the risk of TNBC (ref. ${ }^{42}$ ). However, diet as a modifiable protective factor against TNBC has not been studied in detail. A study by Go et al. suggests that healthy dietary habits, such as adequate consumption of vegetables, vegetable fats and nuts, are associated with a reduced risk of TNBC ( ref. $^{43}$ ). Regular exercise and daily consumption of green tea ( $\geq 100$ grams of tea leaves) showed a protective association (OR 0.54) and improved survival in women with TNBC (ref. ${ }^{44}$ ).

Epidemiological studies have revealed that populations of many countries with high consumption of fish and seafood have low prevalence rates of particular types of cancers such as breast, colorectal and prostate cancers. The results of investigations on extracts and compounds from fish (cod, anchovy, eel and also fish protein hydrolysates), molluscs (mussel, oyster, clams and abalone) and sea cucumbers and their in vivo/in vitro anticancer/ antitumor activities support the benefits of these edible marine organisms ${ }^{45}$.

\section{Night work influence}

Studies have been published suggesting a moderate association between night work and BC. In 2007, the WHO concluded that shift work impairs human circadian biological rhythms and is likely to contribute to the process of carcinogenesis. A meta-analysis of prospective studies involving more than one million women failed to confirm the association between night work and the risk of $\mathrm{BC}$ (RR 1.00) $\left(\right.$ ref. $\left.^{46}\right)$. A low association between night work and BC (RR 1.77) was reported by Swedish authors but only after prolonged exposure of more than 20 years ${ }^{47}$. However, night work influence on the TNBC subtype has not been studied. Exposure to artificial light at night, suppressed melatonin secretion in disturbed sleep patterns and decreased amount of sleep are known as fac- tors harmful to health as confirmed by epidemiological studies. Night work affects a large part of the workforce (75\%) in developed countries. Therefore, the International Agency for Research on Cancer classified shift work into group 2A as a "probable human carcinogen" (ref. ${ }^{48}$ ).

\section{Infectious agents}

Recent studies have pointed to an association between infections with human papillomavirus (HPV) and EpsteinBarr virus (EBV) and carcinogenesis in the breast ${ }^{49}$. The role of HPV in mammary gland carcinogenesis is a matter of research. It has recently been shown that $29 \%$ of BC cases are HPV-positive (subtypes 16, 18 and 33). HPV sequences were detected by PCR in cell lines of malignant mammary gland and lymph node samples. By contrast, benign breast tissue samples were not HPV-positive ${ }^{49}$. These findings support the hypothesis of the oncogenic properties of HPV and association with BC. A meta-analysis of 22 case-control studies has revealed that HPV infection increases the risk of BC (RR 4.02; 95\% CI 2.42-6.68) $\left(\right.$ ref. ${ }^{50}$ ). In TNBC, the prevalence of HPV positivity in tumour samples was $15 \%$ in a recent study ${ }^{51}$.

Many questions concerning the association remain unanswered. The level of risk depends on the tissue type (areolar, ductal), virus subtype and genetic background of the patient. HPV infection adds a new element to the mosaic of risk factors, the role of which will only be analysed in the future; and so will be the epidemiological context of possible HPV infection in women.

Epstein-Barr virus is aetiologically linked to Burkitt lymphoma, nasopharyngeal carcinoma, post-transplant lymphomas, Hodgkin disease, and possibly other tumours. However, the association of oncogenic EBV with BC is a matter of debate. The presence of the EBV genome in $\mathrm{BC}$ cases and its association with the clinicopathological features is being studied. A possible causal association of EBV in BC cases including TNBC is suggested by a high frequency of EBV positivity detected in tumour cells ${ }^{52}$. The presence of EBV was found to be a pathogenic factor in BC. The effect of EBV-positive BC on the prognosis has been examined. EBV positivity was found to exert no effect on survival, despite its association with aggressive BC phenotypes ${ }^{53}$. Although the prevalence of coinfection with HPV or EBV in BC patients is low, there is a possibility of a synergistic carcinogenic effect of different viruses in the development of $\mathrm{BC}$ disease ${ }^{54}$. The risk factors are listed in a table (Table 1).

\section{PUTATIVE SCREENING METHODS FOR TNBC}

Cell-free DNA from peripheral blood could be a suitable material for new screening methods, especially for early detection of cancer. As for the epigenetic-markerbased system, 12 novel markers (JAK3, RASGRF1, CPXM1, SHF, DNM3, CAV2, HOXA10, B3GNT5, ST3GAL6, DACH1, $P 2 R X 3$, and chr8:23572595) for detecting BC were identified by methylation array analysis. The sensitivity and specificity of the model were 0.862 and 0.827 , respec- 
tively. The epigenetic-marker-based system distinguished BC patients from healthy volunteers with high accuracy ${ }^{55}$.

In the development of this droplet digital methylation-specific PCR (ddMSP) system, twenty-five TNBC tumours were included so it also detects TNBC with a detection index similar to other BC types. The dominant markers for TNBC are ST3GAL6, DACH1, and chr8:23572595. As detection rates of early BC using this system were comparable with those of mammography screening, this system would be beneficial as an optional screening method. The authors plan to focus their research on the role of the ddMSP system as an alternative screening approach in patients with and carriers of the $B R C A$ mutation $^{55}$.

\section{CONCLUSIONS}

Results of epidemiological studies suggest that a large proportion of TNBC cases could be predicted early depending on the existing risk of the condition using traditional risk factors. However, there are new emerging protective factors playing a role in TNBC. These include micronutrients (vitamin $\mathrm{D}$, folate, zinc and $\beta$-carotene) or long-term consumption of soya, seafood or green tea. New potential risk factors are night work and the viral infectious agents HPV and EBV.

As part of primary prevention, women's awareness of the potential risks of the development of TNBC must be continuously increased. The general public should be repeatedly reminded of guidance for preventive measures including availability of mammographic screening. In the future, new screening methods may be used, for example, the epigenetic-marker-based system. An effort to predict the risk might lead to a positive shift in the morbidity and mortality of TNBC.

\section{Search strategy and selection criteria}

The PubMed online database was used to search relevant reviews and original articles. Furthermore, we also focused on some statistical information from current online databases concerning estimated cancer incidence, prevalence and mortality worldwide.

Acknowledgement: This work was supported by the grants Comprehensive Study at the Issue of Oncological Diseases (No. 991100531/39 Vaduz), NV16-31997A and RVO: FNO1, 00098892 from the Czech Ministry of Health, NPS I LO1304 and RVO: 61989592 from the Czech Ministry of Education, IGA LF 2017016.

Author contributions: DH, KB: manuscript writing; KC, LS, JV, HK: literature search, critical review of the manuscript.

Conflict of interest statement: The authors state that there are no conflicts of interest regarding the publication of this article.

\section{REFERENCES}

1. Ferlay J, Soerjomataram I, Ervik M, Dikshit R, Eser S, Mathers C, Rebelo M, Parkin DM, Forman D, Bray, F. GLOBOCAN 2012 v1.0, Cancer Incidence and Mortality Worldwide: IARC CancerBase No. 11 [Internet]. Lyon, France: International Agency for Research on Cancer; 2013. Available from: http://globocan.iarc.fr, accessed on 30.07.2017.

2. Vankova E, Zvolsky M, Pasingerova R, Noland D, Typltova J. Novotvary 2011. [online document]. Institute of Health Information and Statistics of the Czech Republic 2015 [cited 2016 Dec 20]. Available from: http://www.uzis.cz/katalog/zdravotnicka-statistika/novotvary.

3. Ghoncheh M, Soltani S, Salehinya H. Disparities in Incidence and Mortality of Breast Cancer. Iran J Public Health 2016;45(2):270-1.

4. Howell A, Anderson AS, Clarke RB, Duffy SW, Evans DG, Garsia-Closas M, Gescher AJ, Key TJ, Saxton JM, Harvie MN. Risk determination and prevention of breast cancer. Breast Cancer Res 2014;16:446.

5. Bouchalova K, Cizkova M, Cwiertka K, Trojanec R, Hajduch M. Triple negative breast cancer - current status and prospective targeted treatment based on HER1 (EGFR), TOP2A and C-MYC gene assessment. Biomed Pap Med Fac Univ Palacky Olomouc Czech Repub 2009;153(1):13-18.

6. Bouchalova K, Kharaishvili G, Bouchal J, Vrbkova J, Megova M, Hobilkova A. Triple negative breast cancer - BCL2 in prognosis and prediction. Review. Current Drug Targets 2014;15(12):1166-75.

7. Robson M, Im SA, Senkus E, Xu B, Domchek SM, Masuda N, Delaloge S, Li W, Tung N, Armstrong A, Wu W, Goessl C, Runswick S, Conte P. Olaparib for metastatic breast cancer in patients with a germline BRCA mutation. N Engl J Med 2017;377(6):523-33.

8. Wagner AD, Thomssen C, Haerting J, Unverzagt S. Vascularendothelial-growth-factor (VEGF) targeting therapies for endocrine refractory or resistant metastatic breast cancer. Cochrane Database Syst Rev 2012;7:CD008941.

9. Bouchalova K, Svoboda M, Kharaishvili G, Vrbkova J, Bouchal J, Trojanec R, Koudelakova V, Radova L, Cwiertka K, Hajduch M, Kolar Z. BCL2 is an independent predictor of outcome in basal-like triplenegative breast cancers treated with adjuvant anthracycline-based chemotherapy. Tumor Biology 2015;36(6):4243-52.

10. Warner ET, Colditz GA, Palmer JR, Partridge AH, Rosner BA, Tamimi RM. Reproductive factors and risk of premenopausal breast cancer by age at diagnosis: are there differences before and after age 40 ? Breast Cancer Res Treat 2013;142(1):165-75.

11. Liu Y, Tobias DK, Stugeon KM, Rosner B, Malik V, Cesperedes E, Joshi $A D$, Eliassen $A H$, Colditz GA. Physical activity from menarche to first pregnancy and risk of breast cancer. Int J Cancer 2016;139(6):122330.

12. Giudici F, Scaggiante B, Scomersi S, Bortul M, Tonutti M, Zanconati F. Breastfeeding: a reproductive factor able to reduce the risk of luminal B breast cancer in premenopausal White women. Eur J Cancer Prev 2017;26(3):217-24.

13. Kaaks R, Tikk K, Sookthai D, Schock H, Johnson T, Tjønneland A, Olsen A, Overvad K, Clavel-Chapelon F, Dossus L, Baglietto L, Rinaldi S, Chajes V, Romieu I, Boeing H, Schütze M, Trichopoulou A, Lagiou P, Trichopoulos D, Palli D, Sieri S, Tumino R, Ricceri F, Mattiello A, Buckland G, Ramón Quirós J, Sánchez MJ, Amiano P, Chirlaque MD, Barricarte A, Bas Bueno-de-Mesquita $\mathrm{H}$, van Gils $\mathrm{CH}$, Peeters $\mathrm{PH}$, Andersson A, Sund M, Weiderpass E, Khaw KT, Wareham N, Key TJ, Travis RC, Merritt MA, Gunter MJ, Riboli E, Lukanova A. Premenopausal serum sex hormone levels in relation to breast cancer risk, overall and by hormone receptor status - results from the EPIC cohort. Int J Cancer 2014;134(8):1947-57.

14. Fourkala EO, Blyuss O, Field H, Gunu R, Ryan A, Barth J, Jacobs I, Zaikin A, Dawnay A, Menon U. Sex hormone measurements using mass spectrometry and sensitive extraction radioimmunoassay and risk of estrogen receptor negative and positive breast cancer: Case control study in UK Collaborative Cancer Trial of Ovarian Cancer Screening (UKCTOCS). Steroids 2016;110:62-9.

15. Islami F, Liu Y, Jemal A, Zhou J, Weiderpass E, Colditz G, Boffetta P, Weiss M. Breastfeeding and breast cancer risk by receptor status-a systematic review and meta-analysis. Ann Oncol 2015;26(12):2398407.

16. Atkinson RL, El-Zein R, Valero V, Lucci A, Bevers TB, Fouad T, Liao W, Ueno NT, Woodward WA, Brewster AM. Epidemiological risk fac- 
tors associated with inflammatory breast cancer subtypes. Cancer Causes Control 2016;27(3):359-66.

17. Ma H, Ursin G, Xu X, Lee E, Togawa K, Duan L, Lu Y, Malone KE, Marchbanks PA, McDonald JA, Simon MS, Folger SG, Sullivan-Halley J, Deapen DM, Press MF, Bernstein L. Reproductive factors and the risk of triple-negative breast cancer in white women and AfricanAmerican women: a pooled analysis. Breast Cancer Res 2017;19(1):6.

18. Paluch-Shimon S, Cardoso F, Sessa C, Balmana J, Cardoso MJ, Gilbert $F$, Senkus E. Prevention and screening in BRCA mutation carriers and other breast/ovarian hereditary cancer syndromes: ESMO Clinical Practice Guidelines for cancer prevention and screening. Ann Oncol 2016;27(suppl 5):v103-v110.

19. Gluz O, Liedtke C, Gottschalk N, Pusztai L, Nitz U, Harbeck N. Triplenegative breast cancer-current status and future directions. Ann Oncol 2009;20(12):1913-27.

20. Greenup R, Buchanan A, Lorizio W, Rhoads K, Chan S, Leedom T, King R, McLennan J, Crawford B, Marcom PK, Hwang ES. Prevalence of BRCA Mutations Among Women with Triple-Negative Breast Cancer (TNBC) in a Genetic Counseling Cohort. Ann Surg Oncol 2013; 20(10):3254-8.

21. Sharma P, Klemp JR, Kimler BF, Mahnken JD, Geier LJ, Khan QJ, Elia M, Connor CS, McGinness MK, Mammen JM, Wagner JL, Ward C, Ranallo L, Knight CJ, Stecklein SR, Jensen RA, Fabian CJ, Godwin AK. Germline BRCA mutation evaluation in a prospective triplenegative breast cancer registry: implications for hereditary breast and/or ovarian cancer syndrome testing. Breast Cancer Res Treat 2014;145(3):707-14.

22. Agranat $S$, Baris $H$, Kedar I, Shochat M, Rizel S, Perry S, Margel D, Sulkes A, Yerushalmi R. Earlier Age of Breast Cancer Onset in Israeli BRCA Carriers-Is it a Real Phenomenon? Breast J 2016;22(6):662-6.

23. Connor J. Alcohol consumption as a cause of cancer. Addiction 2017;112(2):222-8

24. Strumylaite L, Sharp SJ, Kregzdyte R, Poskiene L, Bogusevicius A, Pranys D. The Association of Low-To-Moderate Alcohol Consumption with Breast Cancer Subtypes Defined by Hormone Receptor Status. PLoS One 2015;10(12):e0144680.

25. Shin A, Sandin S, Lof M, Margolis KL, Kim K, Couto E, Adami HO, Weiderpass $\mathrm{E}$. Alcohol consumption, body mass index and breast cancer risk by hormone receptor status: Women' Lifestyle and Health Study. BMC Cancer 2015;15:881.

26. Preyer O, Johansen D, Holly J, Stocks T, Pompella A, Nagel G, Concin $\mathrm{H}$, Ulmer $\mathrm{H}$, Concin $\mathrm{N}$. $\mathrm{\gamma}$-Glutamyltransferase and Breast Cancer Risk Beyond Alcohol Consumption and Other Life Style Factors - A Pooled Cohort Analysis. PLoS One 2016;11(2):e0149122.

27. Ferrari P, Licaj I, Muller DC, Kragh Andersen P, Johansson M, Boeing $\mathrm{H}$. Lifetime alcohol use and overall and cause-specific mortality in the European Prospective Investigation into Cancer and nutrition (EPIC) study. BMJ Open 2014;4(7):e005245

28. Kabat GC, Kim M, Phipps Al, Li Cl, Messina CR, Wactawski-Wende J, Kuller L, Simon MS, Yasmeen S, Wassertheil-Smoller S, Rohan TE. Smoking and alcohol consumption in relation to risk of triple-negative breast cancer in a cohort of postmenopausal women. Cancer Causes Control 2011;22(5):775-83.

29. Ma H, Xu X, Claque J, Lu Y, Togawa K, Wang SS, Clarke CA, Lee E, Park HL, Sullivan-Halley J, Neuhausen SL, Bernstein L. Recreational physical activity and risk of triple negative breast cancer in the California Teachers Study. Breast Cancer Res 2016;18(1):62.

30. Sebastiani F, Cortesi L, Sant M, Lucarini V, Cirilli C, De Matteis E, Marchi I, Negri R, Gallo E, Federico M. Increased Incidence of Breast Cancer in Postmenopausal Women with High Body Mass Index at the Modena Screening Program. J Breast Cancer 2016;19(3):283-91.

31. Brooks JD, John EM, Mellemkjær L, Reiner AS, Malone KE, Lynch CF, Figueiredo JC, Haile RW, Shore RE, Bernstein JL, Bernstein L. Body mass index and risk of second primary breast cancer: the WECARE Study. Breast Cancer Res Treat 2012;131(2):571-80.

32. Brooks JD, John EM, Mellemkjaer L, Lynch CF, Knight JA, Malone KE, Reiner AS, Bernstein L, Liang X, Shore RE, Stovall M, Bernstein JL. Body mass index, weight change, and risk of second primary breast cancer in the WECARE study: influence of estrogen receptor status of the first breast cancer. Cancer Med 2016;5(11):3282-91.

33. Phipps Al, Malone KE, Porter PL, Daling JR, Li Cl. Body size and risk of luminal, HER2-overexpressing, and triple-negative breast cancer in postmenopausal women. Cancer Epidemiol Biomarkers Prev 2008;17(8):2078-86.
34. Phipps Al, Chlebowski RT, Prentice R, McTiernan A, Stefanick ML, Wactawski-Wende J, Kuller LH, Adams-Campbell LL, Lane D, Vitolins M, Kabat GC, Rohan TE, Li Cl. Body size, physical activity, and risk of triple-negative and estrogen receptor-positive breast cancer. Cancer Epidemiol Biomarkers Prev 2011;20(3):454-63.

35. Swisher AK, Abraham J, Bonner D, Gilleland D, Hobbs G, Kurian S, Yanosik MA, Vona-Davis L. Exercise and dietary advice intervention for survivors of triple-negative breast cancer: effects on body fat, physical function, quality of life, and adipokine profile. Support Care Cancer 2015;23(10):2995-3003.

36. Chen P, Li C, Li X, Li J, Chu R, Wang H. Higher dietary folate intake reduces the breast cancer risk: a systematic review and meta-analysis. Br J Cancer 2014;110(9):2327-38.

37. de Batlle J, Ferrari P, Chajes V, Park JY, Slimani N, McKenzie F, Overvad K, Roswall N, Tjønneland A, Boutron-Ruault MC, Clavel-Chapelon F, Fagherazzi G, Katzke V, Kaaks R, Bergmann MM, Trichopoulou A, Lagiou P, Trichopoulos D, Palli D, Sieri S, Panico S, Tumino R, Vineis $P$, Bueno-de-Mesquita $H B$, Peeters $P H$, Hjartåker $A$, Engeset $D$, Weiderpass E, Sánchez S, Travier N, Sánchez MJ, Amiano P, Chirlaque MD, Barricarte Gurrea A, Khaw KT, Key TJ, Bradbury KE, Ericson U, Sonestedt E, Van Guelpen B, Schneede J, Riboli E, Romieu I. Dietary folate intake and breast cancer risk: European prospective investigation into cancer and nutrition. J Natl Cancer Inst 2015;107(1):dju367.

38. Agnoli C, Grioni S, Krogh V, Pala V, Allione A, Matullo G, Di Gaetano C, Tagliabue G, Pedraglio S, Garrone G, Cancarini I, Cavalleri A, Sieri S. Plasma Riboflavin and Vitamin B-6, but Not Homocysteine, Folate, or Vitamin B-12, Are Inversely Associated with Breast Cancer Risk in the European Prospective Investigation into Cancer and NutritionVarese Cohort. J Nutr 2016;146(6):1227-34.

39. Yao S, Kwan ML, Ergas IJ, Roh JM, Cheng TD, Hong CC, McCann SE, Tang L, Davis W, Liu S, Quesenberry CP Jr, Lee MM, Ambrosone CB, Kushi LH. Association of Serum Level of Vitamin D at Diagnosis With Breast Cancer Survival: A Case-Cohort Analysis in the Pathways Study. JAMA Oncol 2017;3(3):351-7.

40. Amadori D, Serra P, Masalu N, Pangan A, Scarpi E, Bugingo AM, Katabalo D, Ibrahim T, Bongiovanni A, Miserocchi G, Spadazzi C, Liverani C, Turri V, Tedaldi R, Mercatali L. Vitamin D receptor polymorphisms or serum levels as key drivers of breast cancer development? The question of the vitamin D pathway. Oncotarget 2017;8(8):1314256.

41. Lee E, Levine EA, Franco VI, Allen GO, Gong F, Zhang Y, Hu JJ. Combined genetic and nutritional risk models of triple negative breast cancer. Nutr Cancer 2014;66(6):955-63.

42. Guo X, Cai Q, Bao P, Wu J, Wen W, Ye F, Zheng W, Zheng Y, Shu $X O$. Long-term soy consumption and tumor tissue MicroRNA and gene expression in triple-negative breast cancer. Cancer 2016;122(16):2544-51.

43. Go Y, Chung M, Park Y. Dietary Patterns for Women With Triple-negative Breast Cancer and Dense Breasts. Nutr Cancer 2016;68(8):1281-8.

44. Bao PP, Zhao GM, Shu XO, Peng P, Cai H, Lu W, Zheng Y. Modifiable Lifestyle Factors and Triple-negative Breast Cancer Survival: A Population-based Prospective Study. Epidemiology 2015;26(6):90916.

45. Correia-da-Silva M, Sousa E, Pinto MM, Kijjoa A, Kijjoa A. Anticancer and cancer preventive compounds from edible marine organisms. Semin Cancer Biol 2017;46:55-64.

46. Travis RC, Balkwill A, Fensom GK, Appleby PN, Reeves GK, Wang XS, Roddam AW, Gathani T, Peto R, Green J, Key TJ, Beral V. Night Shift Work and Breast Cancer Incidence: Three Prospective Studies and Meta-analysis of Published Studies. J Natl Cancer Inst 2016;108(12):djw169.

47. Åkerstedt T, Knutsson A, Narusyte J, Svedberg P, Kecklund G, Alexanderson K. Night work and breast cancer in women: a Swedish cohort study. BMJ Open 2015;5(4):e008127.

48. Touitou Y, Reinberg A, Touitou D. Association between light at night, melatonin secretion, sleep deprivation, and the internal clock: Health impacts and mechanisms of circadian disruption. Life Sci 2017;173:94-106.

49. Wang T, Chang P, Wang L, Yao Q, Guo W, Chen J, Yan T, Cao Ch. The role of human papillomavirus infection in breast cancer. Med Oncol 2012;29(1):48-55.

50. Bae JM, Kim EH. Human papillomavirus infection and risk of breast cancer: a meta-analysis of case-control studies. Infect Agent Cancer 2016;14:11-4. 
51. Piana AF, Sotgiu G, Muroni MR, Cossu-Rocca P, Castiglia P, De Miglio MR. HPV infection and triple-negative breast cancers: an Italian casecontrol study. Virol J 2014;11:190.

52. Pai T, Gupta S, Gurav M, Nag S, Shet T, Patil A, Desai S. Evidence for the association of Epstein-Barr Virus in breast cancer in Indian patients using in-situ hybridization technique. Breast J 2018;24(1):1622.

53. Mazouni C, Fina F, Romain S, Ouafik L, Bonnier P, Martin PM. Outcome of Epstein-Barr virus-associated primary breast cancer. Mol Clin Oncol 2015:3(2):295-8.
54. Naushad W, Surriya O, Sadia H. Prevalence of EBV, HPV and MMTV in Pakistani breast cancer patients: A possible etiological role of viruses in breast cancer. Infect Genet Evol 2017;54:230-7.

55. Uehiro N, Sato F, Pu F, Tanaka S, Kawashima M, Kawaguchi K, Sugimoto M, Saji S, Toi M. Circulating cell-free DNA-based epigenetic assay can detect early breast cancer. Breast Cancer Res 2016;18(1):129. 